\title{
Gender differences in counterregulation to hypoglycaemia
}

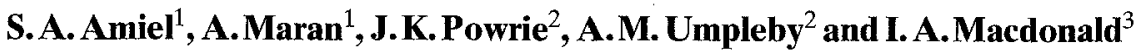 \\ ${ }^{1}$ Unit for Metabolic Medicine, Guy's Hospital, London, UK \\ ${ }^{2}$ Department of Endocrinology and Chemical Pathology, St Thomas's Hospital, United Medical \\ and Dental Schools of Guy's and St Thomas's Hospitals, London, UK \\ ${ }^{3}$ Department of Physiology and Pharmacology, University of Nottingham, Nottingham, UK
}

\begin{abstract}
Summary. To investigate the effect of gender on catecholamine responses to hypoglycaemia, single-step euglycaemichypoglycaemic clamps have been performed in 14 healthy men and 17 women. Adrenaline responses were $44 \%$ lower in females $(p<0.01)$ and noradrenaline $17 \%$ lower $(p=0.08)$. In response to low-dose intravenous insulin infusion $\left(0.3 \mathrm{mU} \cdot \mathrm{kg}^{-1} \cdot \mathrm{min}^{-1}\right)$, plasma glucose fall and counterregulation in seven men and seven women had a different course $(p<0.001)$, with different glucose kinetics. In men, endogenous glucose output recovered quickly to levels that exceeded basal; in women suppression of endogenous glucose output was more prolonged, without rates ever exceeding basal $(p<0.05)$. Peripheral glucose uptake was stimu-
\end{abstract}

lated in men only. The hormones of acute glucose counterregulation (catecholamines and glucagon) did not differ between the sexes during this challenge, the catecholamine response in the women being supported by the continuous fall in plasma glucose. These results suggest that: 1) catecholamine responses to moderately controlled hypoglycaemia are diminished in women, and 2) peripheral insulin sensitivity in men is enhanced over that of women but hepatic sensitivity to insulin may be greater in women.

Key words: Counterregulation, hypoglycaemia, gender, catecholamines.
During prolonged fasting, women achieve lower blood glucose levels than do men [1]. Yet differences in responses to acute hypoglycaemia have not been investigated and studies into the physiology and pathophysiology of counterregulation to hypoglycaemia commonly include men and women in a single group. The present investigations were designed to investigate responses to hypoglycaemia in men and women separately. We chose to use the euglycaemic-hypoglycaemic insulin clamp [2], in order to measure catecholamine responses to a single reproducible hypoglycaemic stimulus in healthy men and women and a low-dose insulin infusion (without exogenous glucose infusion) in order to examine overall ability spontaneously to counterregulate [3]. Stable isotopes have been used to examine glucose kinetics in the latter study.

\section{Subjects, materials and methods}

Forty-five age-matched healthy men and women were recruited for study. All subjects were consuming a weight-maintaining diet. None of the subjects was an athlete and none had a family history of diabetes mellitus. Subjects were asked to refrain from alcohol for $24 \mathrm{~h}$ and from smoking for $12 \mathrm{~h}$ before study. Each subject performed one study only.
Subjects were admitted to the research units in the morning after an overnight fast. Two intravenous cannulae were inserted using intradermal lignocaine as a local anaesthetic. One cannula, for infusion of test substances, was inserted into an antecubital vein, the second, for the sampling of arterialised venous blood, was placed retrograde into a dorsal vein of a hand placed in a box of air heated to $55-60^{\circ} \mathrm{C}$ [4]. All subjects rested for at least $30 \mathrm{~min}$ after the insertion of intravenous lines before baseline blood sampling. All studies were conducted with the subjects supine or semi-recumbent.

Subjects gave written informed consent prior to each study. All protocols were approved either by the ethical committee of the University of Nottingham Medical School, or by the Lewisham and North Southwark Committee of Ethical Practice, London, and studies were conducted in accordance with the Helsinki Declaration.

Study one: euglycaemic-hypoglycaemic insulin clamp: (14 men, aged 20 to 34 years, BMI $20-26.6 \mathrm{~kg} / \mathrm{m}^{2}$ and 17 women, aged between 22 and 33 years with BMI ranging from 21 to $27 \mathrm{~kg} / \mathrm{m}^{2}$ ).

A primed continuous infusion of human insulin (human Actrapid; Novo-Nordisk, Copenhagen, Denmark, made up in a $4 \%$ solution of the subject's blood in $0.9 \% \mathrm{NaCl}$ ) was begun at a maintenance rate of $60 \mathrm{mU} / \mathrm{m}^{2}$ per min. Blood glucose was maintained at euglycaemic levels for $30 \mathrm{~min}$ by means of a variable rate glucose infusion. The blood glucose was then allowed to fall to $2.5 \mathrm{mmol} / \mathrm{l}$ where it was held by further adjustment of the glucose infusion for $30 \mathrm{~min}$. Blood glucose was measured every $10 \mathrm{~min}$ and additional samples for later measurement of catecholamine levels were taken at baseline, at $30 \mathrm{~min}$ and at $60 \mathrm{~min}$. 
Study two: low-dose insulin infusion: (seven men, aged between 23 and 45 years, BMI 20.9 to $25.1 \mathrm{~kg} / \mathrm{m}^{2}$ and seven women aged 25 to 36 years $(p=0.59)$, BMI 20.1 to $24.3 \mathrm{~kg} / \mathrm{m}^{2}(p=0.53)$. Women on the contraceptive pill were excluded from study.

A primed (100:1) continuous infusion of $\left[6-6^{2} \mathrm{H}\right]_{2}$ glucose (Tracer Technologies, Somerville, Mass., USA) was started and run at $0.0375 \mathrm{mg} \cdot \mathrm{kg}^{-1} \cdot \mathrm{min}^{-1}$ for $120 \mathrm{~min}$. During this time, measurement of the four-choice reaction time (a test of psychomotor performance in which the subject has repeatedly to clear a computer generated signal from a quadrant of the computer screen by depressing the corresponding button on the key pad) was made at least four times, until reproducible test results were obtained. Performance on this test tends to improve in terms of speed and accuracy of response after the first attempt but after three to five measurements remains stable. Baseline blood samples were taken over $30 \mathrm{~min}$ to ensure plasma glucose tracer enrichment had reached steady state. Thereafter, a 3-h infusion of rapid acting human insulin (human Actrapid; Novo-Nordisk, Copenhagen, Denmark) was started at $0.6 \mathrm{mU} \cdot \mathrm{kg}^{-1} \cdot \mathrm{min}^{-1}$ for $5 \mathrm{~min}$, followed by $0.3 \mathrm{mU} \cdot \mathrm{kg}^{-1} \cdot \mathrm{min}^{-1}$ for $175 \mathrm{~min}$. Blood glucose was monitored every $5 \mathrm{~min}$ for the first hour and every $10 \mathrm{~min}$ thereafter. Additional blood samples were taken for later measurement of catecholamines, glucagon, growth hormone, cortisol, insulin and C-peptide. The study was stopped (and exogenous glucose given) if blood glucose fell below $2.6 \mathrm{mmol} / \mathrm{l}$ for more than $10 \mathrm{~min}$ and the subject was either excessively uncomfortable or drowsy. At regular intervals throughout the study, subjects were asked to complete a symptom questionnaire (12 symptoms related to hypoglycaemia which were to be ranked on a linear analogue scale from $0=$ none, to $6=$ very severe) and four-choice reaction time was measured.

\section{Measurements and calculations}

During clamps and insulin infusions blood glucose was measured at the bedside using a glucose oxidase method (Yellow Springs Glucose Analyser; Yellow Springs Instrument Corporation, Yellow Springs, Ohio, USA). For measurement of glucose kinetics during the insulin infusion study, plasma was separated as soon as possible, frozen and stored at $-70^{\circ} \mathrm{C}$ until enrichment of plasma glucose by tracer could be measured by gas chromatograph mass spectroscopy [5]. This was performed on a V.G. Trio-2 580 (Hewlett Packard, Woking, Surrey, UK) using selected ion monitoring of a glucose acetate boronate derivative [6]. The ions monitored were of molecular mass 297 (representing $\mathrm{M}-\mathrm{C}_{4} \mathrm{H}_{9}+$ ) and 299 (the corresponding fragment enriched with two deuterium atoms). The intra-assay coefficient of variation of the measurement of isotope enrichment was less than $2 \%$. Glucose was measured as above in each plasma sample. Catecholamines were measured using HPLC [7]; cortisol, glucagon, growth hormone and C-peptide and free insulin using radioimmunoassays [8]. Intra-assay variation was not greater than $9 \%$ for any assay.

Symptom scores were expressed as the increase over the baseline score for autonomic symptoms (sweating, feeling nervous, heart pounding, trembling or shaking, tingling), for neuroglycopenic symptoms (difficulty in thinking, blurred vision, dizziness, tiredness, faintness) and for hunger [9].

For analysis of the four-choice reaction time, both deterioration in speed (expressed as a $5 \%$ increase in the mean time for a correct response) and accuracy (expressed as a $2 \%$ reduction in the proportion of responses that were correct) were calculated.

Glucose kinetics have been analysed using modifications [5] of the non-steady-state adaptation [10] of Steele's equation [11].

\section{Statistical analysis}

Demographic data are given as ranges. All results are given as the mean \pm SEM. The peak catecholamine responses to the clamped hypoglycaemic stimulus of Study one have been compared by unpaired Student's $t$-tests. The effect of gender on the responses to the low- dose insulin of Study two has been analysed using a multivariate analysis of variance for repeated measures (MANOVA), with unpaired Student's $t$-testing on log-transformed data to ascertain significance of differences between the peaks of responses. Paired Student's $t$-testing has been used to establish the time point at which a significant difference over basal values occurred. Analyses were made using SSPS and $t$-testing was done using Minitab. $P$ values of less than 0.05 were considered significant.

\section{Results}

\section{Study one: catecholamine responses to a fixed hypoglycaemic stimulus}

During the clamps, blood glucose fell from baseline over $30 \mathrm{~min}$ and was maintained at $2.5 \mathrm{mmol} / 1$ for the final $30 \mathrm{~min}$ of each study (coefficient of variation range 1.5$5 \%$ ), with no significant differences between the stimulus in men or women (Fig. 1). Adrenaline levels were slightly higher at the start of the clamp in men $(0.3 \pm 0.03 \mathrm{nmol} / \mathrm{l}$ vs $0.2 \pm 0.03, p<0.05)$ but were no different between the sexes by $30 \mathrm{~min}(0.75 \pm 0.21 \mathrm{nmol} / \mathrm{l}$ in men vs $0.63 \pm 0.16$ in women). At the end of the hypoglycaemic stimulus at $60 \mathrm{~min}$, adrenaline levels rose to $3.2 \pm 0.5 \mathrm{nmol} / 1$ in the men but only to $1.8 \pm 0.35 \mathrm{nmol} / 1$ in the women $(p<0.01)$. There was very little overlap between the two groups. Only 2 of the 14 men had a response of less than $2 \mathrm{nmol} / 1$ (1.95 and 1.66), while only 2 of the 17 responses in the women exceeded $1.66 \mathrm{nmol} / \mathrm{l}$. The noradrenaline response was also higher in men, rising from $1.14 \pm 0.11$ to $1.61 \pm$ $0.09 \mathrm{nmol} / \mathrm{l}(p<0.01)$, compared with virtually no response in women $(1.30 \pm 0.12$ to $1.33 \pm 0.13)$, although the difference between the $60 \mathrm{~min}$ values did not achieve significance $(p=0.08)$.

\section{Study two: glucose kinetics and counterregulation during insulin infusion}

Basal plasma insulin levels were $8 \pm 1 \mathrm{mU} / 1$ in men, $6 \pm 1 \mathrm{mU} / \mathrm{ml}$ in women $(p=0.5)$ and rose to steadystate levels of $18 \pm 1 \mathrm{mU} / \mathrm{l}$ and $16 \pm 1 \mathrm{mU} / \mathrm{l}$, respectively, $p=0.16)$. C-peptide fell progressively from $0.42 \pm$

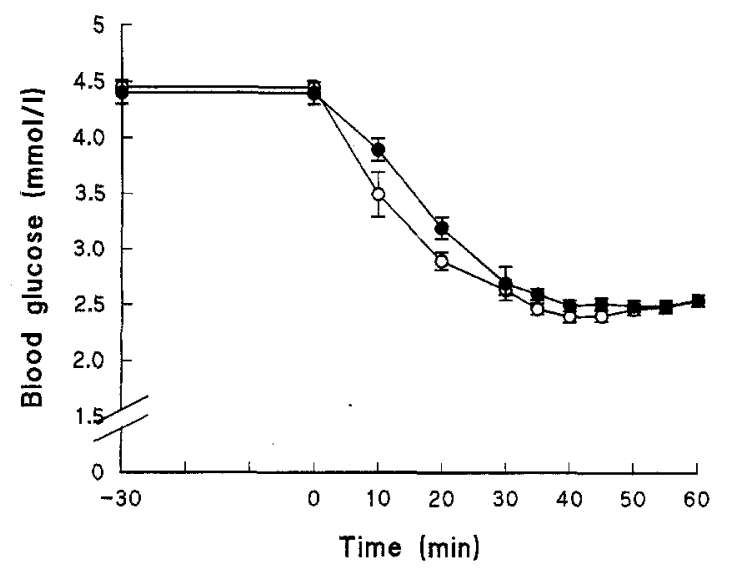

Fig. 1. Glucose profiles (mean \pm SEM) from single-step hypoglycaemic clamps in men $(-)$ and women $(O)$. The hypoglycaemic stimulus was the same in each group 


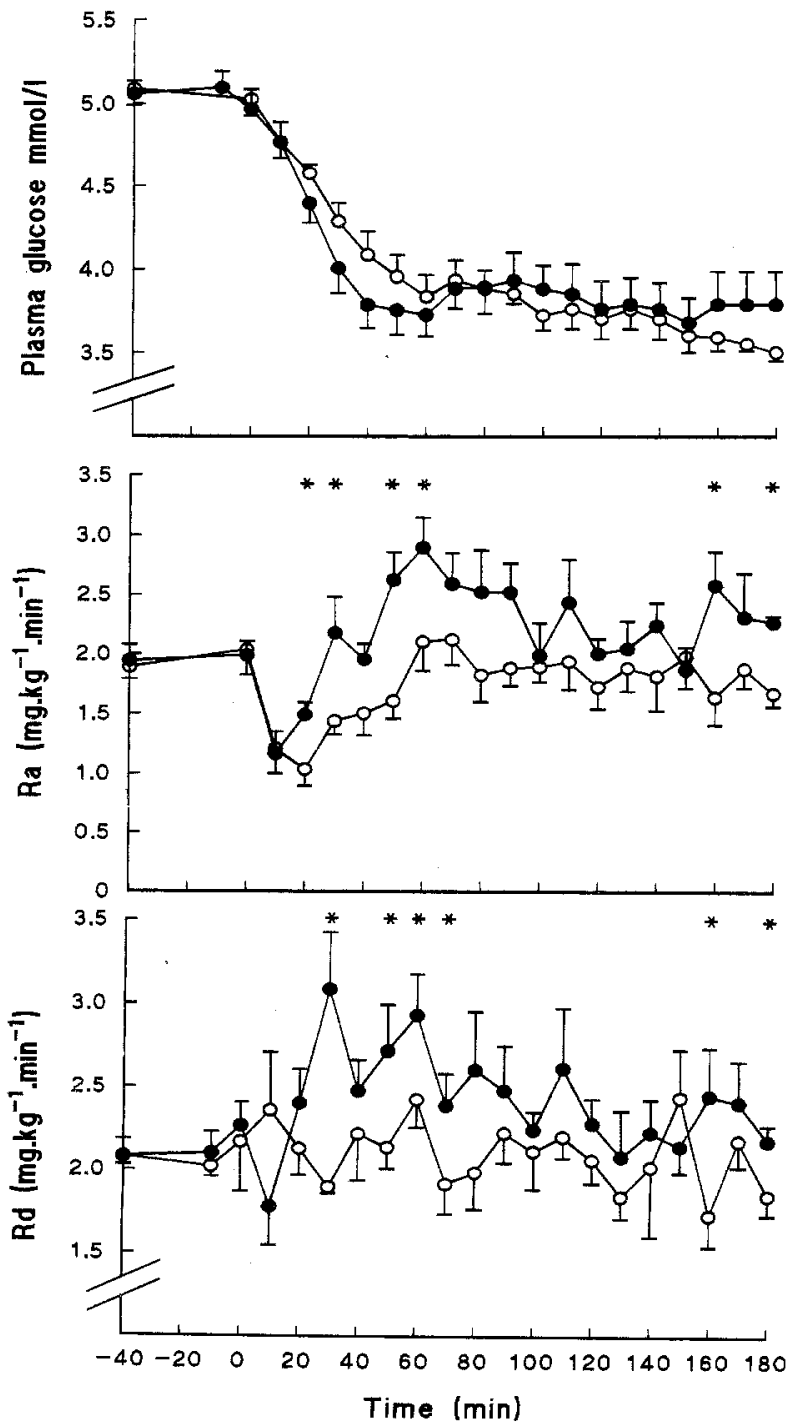

Fig. 2. Plasma glucose (top), rate of endogenous glucose production ( $\mathrm{Ra}$, middle panel) and rate of glucose disappearance $(\mathrm{Rd}$, lower panel) during low-dose insulin infusion in men $(\bullet)$ and women $(0)$, $* p<0.05$

$0.04 \mathrm{nmol} / 1$ in both groups to $0.09 \pm 0.02 \mathrm{nmol} / \mathrm{l}$ in men and $0.07 \pm 0.01 \mathrm{nmol} / \mathrm{l}$ in women $(p=0.29)$. The study in one subject (male), was stopped at $150 \mathrm{~min}$, despite stability of plasma glucose, because of severe symptoms.

The plasma glucose responses to the mild peripheral hyperinsulinaemia (Fig.2, top panel) were significantly different (MANOVA F3.72, $p<0.001$ ). Plasma glucose fell in both groups during the initial $40 \mathrm{~min}$, but in the men there was an initial rapid fall, followed by stabilisation after $30 \mathrm{~min}$, whereas in women a slow decline continued. Suppression of endogenous glucose production ( $\mathrm{Ra}$, Fig.2, middle panel) was more prolonged in the women (MANOVA sex alone $F 6.09, p=0.03$, sex by time $F 1.67$, $p<0.05)$. In men, there was a rapid recovery of endogenous glucose output which was restored to basal values by $30 \mathrm{~min}$ (cf. $60 \mathrm{~min}$ in women) and then rebounded to values in excess of basal by $50 \mathrm{~min}(2.64 \pm 0.23$ vs $1.99 \pm 0.12 \mathrm{mg} / \mathrm{kg}$ per $\mathrm{min}, p=0.03$ ) which did not occur in women. Peripheral glucose uptake (Fig.2, lower panel)
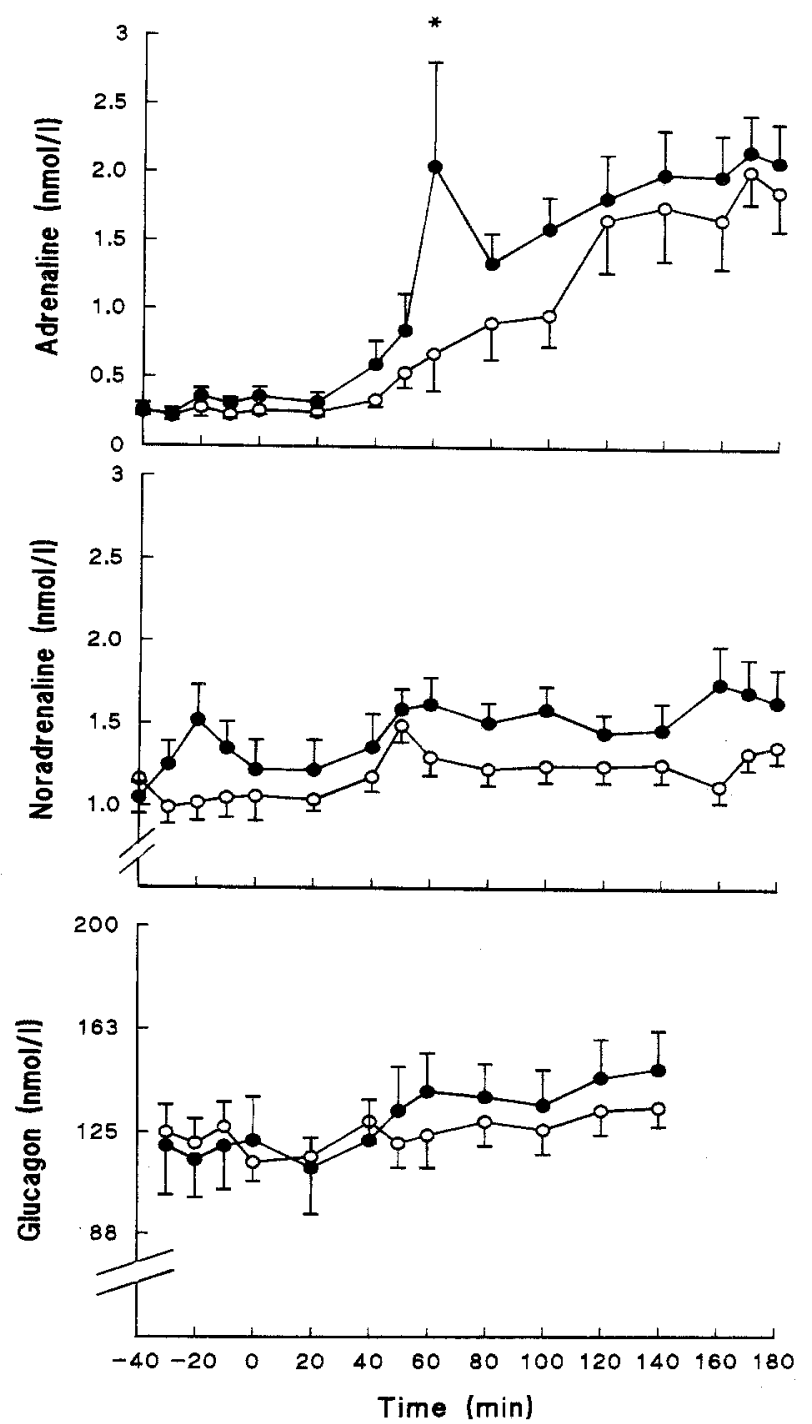

Fig.3. Responses of the hormones of acute glucose counterregulation (adrenaline in top, noradrenaline in the middle and glucagon in the lower panels) during low-dose insulin infusion in men $(\bullet)$ and women (O), ${ }^{*} p<0.05$

was stimulated only in men $(F 1.73, p<0.03)$, and occurred by $30 \mathrm{~min}$. In contrast, there was no stimulation of peripheral glucose uptake in women.

The responses of the hormones of acute counterregulation (adrenaline, noradrenaline and glucagon, Fig. 3) were, not significantly different overall, although the adrenaline response (Fig. 3, upper panel) of the men was more brisk and at 60 min exceeded that of the women $(p<0.03)$. The overall growth hormone response of men and women were not different although a peak response at $120 \mathrm{~min}$ was higher in women $(p=0.01)$.

Adrenergic symptom scores increased by 2 to 7 points in four women and by 2 to 4 points in four men; neuroglycopenic scores increased by between 2 and 5 points in four women and in three men. MANOVA showed no significant differences in these responses between the two sexes. Hunger, analysed separately occurred in all but one (male) subject, with an increase over baseline of 1 to 3 points in the men and 1 to 4 points in the women. This re- 
sponse was slightly greater in the men (MANOVA sex by time $F 2.55, p=0.01$ ). Deterioration in performance of the four-choice reaction time, defined as a $5 \%$ or more increase in the mean correct time or a decrease in correct responses of $2 \%$ or more, or both, occurred in all subjects, at a plasma glucose of $3.8 \pm 0.3 \mathrm{mmol} / \mathrm{l}$ in men and $3.7 \pm 0.1 \mathrm{mmol} / \mathrm{l}$ in the women $(p=0.8)$. In many cases the deterioration was transient, with recovery to baseline in four of the women and five of the men.

\section{Discussion}

The well-described ability of healthy women to achieve and sustain greater degrees of hypoglycaemia during prolonged fasting [1] has not previously been examined. Indeed, male and female subjects are commonly mixed in investigations of responses to hypoglycaemia. Our data suggest, however, that there are important differences between healthy men and women in their responses to exogenous insulin, in their responses to hypoglycaemia and in their ability to counterregulate.

We have documented that healthy women show a greatly diminished adrenaline response to moderately controlled hypoglycaemia during hyperinsulinaemia. This finding is in agreement with preliminary reports from the laboratories of other investigators, also using an insulin clamp technique to apply a reproducible hypoglycaemic stimulus to all subjects $[12,13]$. One of those reports suggests that the greater catecholamine responses in men to a fixed degree of moderate hypoglycaemia is due to triggering of the responses at higher glucose levels than in women, who sustain greater degrees of hypoglycaemia without response [13]. It is possible that responses to more profound degrees of hypoglycaemia eliminate this difference between men and women and that the use of the moderate stimulus of blood glucose clamped at $2.5 \mathrm{mmol} / \mathrm{l}$ allowed the difference to be detected.

The clamp technique is popular in the investigation of responses to hypoglycaemia because it ensures that the hypoglycaemic stimulus is always the same. However, precisely because the investigator has control over the degree of glucose fall, the overall ability of the subject to counterregulate cannot be measured. To investigate the physiological relevance of the gender differences in catecholamine response to hypoglycaemia, we examined the effect of low-dose insulin infusion in healthy men and women.

In men, the low-dose insulin infusion initially supressed endogenous (primarily hepatic) glucose production and stimulated peripheral glucose uptake, with a brisk fall in plasma glucose. The initial fall was secondary to the shut down of hepatic glucose output with peripheral glucose uptake rate also falling initially in response to the lower plasma glucose. Counterregulation occurred as a result of vigorous restimulation of the liver as well as a gradual reduction in peripheral glucose uptake. In women, only the hepatic effects of insulin were noted and recovery of hepatic glucose production was less vigorous. In the face of similar hormonal responses, these results suggest that peripheral insulin sensitivity in men is greater than that in women (perhaps because of their lower fat: muscle ratio,
[14]), but hepatic insulin sensitivity may be greater in women. A differential response of pancreatic insulin or glucagon, or both, cannot be ruled out by these studies.

In both sexes, recovery of hepatic glucose output preceded any change in circulating hormones, suggesting a greater effect of autoregulation than is usually believed to be the case, although an intraportal rise of glucagon cannot be excluded. Furthermore, the fall in C-peptide which occurred in both sexes reflects a counterregulatory reduction in pancreatic insulin, so that portal insulin levels may have fallen during the hypoglycaemia. In this case, the initial suppression of the liver either preceded any fall in pancreatic insulin and was a result of a net increase in portal levels or was a response to hyperinsulinaemia in the hepatic artery.

Unlike the recovery of endogenous glucose production, the eventual fall in peripheral glucose uptake seen in the men began after the adrenaline rise and may have been a response to autonomic stimulation.

In the clamp studies, when the degree of hypoglycaemia was perfectly matched women showed a markedly smaller catecholamine response than men. In the lowdose insulin infusion however, acute hormonal responses did not differ significantly between the sexes, despite the similarity of glucose nadir. This suggests that the catecholamine response in the women during low-dose insulin infusion was enhanced by the altered shape of the glucose curve, providing a more prolonged stimulus than in the men. This interpretation is supported by the earlier response of adrenaline in the men, with the higher peak at 60 min. Alternatively, hypoglycaemia induced by unopposed insulin infusion may provide a more powerful stimulus to counterregulation than hypoglycaemia induced by a clamp technique (during which exogenous glucose is administered), inducing a maximal catecholamine response and overcoming relatively subtle gender differences, as discussed above. Finally, it is possible that the catecholamine response is in fact controlled by the change in glucose kinetics, and in particular by the suppression of hepatic glucose production.

The apparent discrepancy between the catecholamine responses to the two protocols illustrates the difficulties of using uncontrolled hypoglycaemic stimuli to compare responses to hypoglycaemia between individuals. The technique of unopposed insulin administration permits assessment of overall counterregulatory ability. Only when such studies are combined with clamp techniques however can one begin to draw conclusions about components of the overall response.

The prevalence of symptoms of hypoglycaemia in the face of so mild a hypoglycaemic challenge in the low-dose insulin infusion is striking. The glucose levels associated with the symptoms were higher than in previous studies [15-17] but it is possible that the subjective response is diminished in studies using hypoglycaemia controlled by glucose infusion during higher dose insulin infusion. It should be noted that the formal documenting of symptoms does detect quite small subjective changes.

In conclusion, the present work has demonstrated differences in response to hypoglycaemia and insulin infusion between the sexes. Gender related differences in 
counterregulation and in hormonal responses to hypoglycaemia should preclude the mixing of the sexes in unpaired studies of glucoregulation.

Acknowledgements. This work was supported by the Juvenile Diabetes Foundation International and The Special Trustees of Guy's Hospital and by the Hordern Fund. Dr. Maran is in receipt of a Fellowship Award from the Leverhulme Trust. The authors would like to thank Ms H. Archibald RGN for nursing help; Ms N. Jackson, Ms H. Simpson, Ms J. Taylor and Mr. G. Chusney for expert laboratory and technical support and Ms L. Brunton for secretarial services. The work was presented in part at the 13 th Meeting of the International Diabetes Federation in Washington, DC 1991.

\section{References}

1. Merimee TJ, Tyson JE (1974) Stabilization of plasma glucose during fasting. Normal variation in two separate studies. N Engl J Med 291: 1275-1278

2. Amiel SA, Simonson DC, Sherwin RS, Lauritano AA; Tamborlane WV (1987) Exaggerated epinephrine response to hypoglycemia in normal and insulin dependent diabetic children. $J$ Pediatr 110: 832-837

3. Amiel SA, Tamborlane WV, Simonson DC, Sherwin RS (1987) Defective glucose counterregulation after strict glycemic control of insulin dependent diabetes mellitus. New Engl $\mathbf{J}$ Med 316: $1376-1384$

4. Liu D, Moberg E, Kollind K, Lins P-E, Macdonald IA (1992) Arterial, arterilized venous and venous and capillary blood glucose measurements in normal man during hyperinsulinaemic euglycaemia and hypoglycaemia. Diabetologia 35: 287-290

5. Powrie JK, Smith GD, Hennessy TR et al. (1992) Incomplete suppression of hepatic glucose production in NIDDM measured with $6,6-{ }^{2} \mathrm{H}_{2}$ glucose enriched glucose infusion during hyperinsulinaemic euglycaemic clamps. Eur J Clin Invest 22: 244-245

6. Weicko J, Sherman WR (1976) Baroautoregulation of carbohydrates. Correlations between structure and mass spectral behaviour in monoacetylhexose cyclic boronic esters. J Amer Chem Soc 98: 7631-7637

7. Kerr D, Macdonald IA, Tattersall RB (1991) Patients with type 1 diabetes adapt acutely to sustained mild hypoglycaemia. Diabetic Med 8: 123-128
8. Maran A, Macdonald IA, Amiel SA (1992) Evidence for reversibility of defective counterregulation in a patient with insulinoma. Diabetic Med 9: 765-768

9. Hepburn DA, Deary IJ, Patrick AW et al. (1991) Symptoms of acute insulin-induced hypoglycaemia in humans with and without IDDM. Factor analysis based approach. Diabetes Care 14: 949-957

10. De Bodo RC, Steele R, Altszuler N, Dunn A, Bishop JS (1963) On the hormonal regulation of carbohydrate metabolism: studies with C14 glucose. Recent Prog Horm Res 19: 445-482

11. Steele R (1959) Influences of glucose loading and injected insulin on hepatic glucose output. Ann NY Acad Sci 82:420-430

12. Widom B, Kinsley BT, Simonson DC (1991) Women and men differ in counterregulatory hormone responses to hypoglycemia. Diabetes 40 [Suppl 1]: 534A (Abstract)

13. Diamond MP, Jones TW, Caprio S et al. (1991) Gender: a determinant of the adrenergic response to hypoglycemia. Diabetes 40 [Suppl 1]: 27A (Abstract)

14. Forsberg AM, Nilsson E, Werneman J, Bergstrom J, Hultman E (1991) Muscle composition in relation to age and sex. Clin Sci 81: 249-256

15. Amiel SA, Sherwin RS, Simonson DC, Tamborlane WV (1988) Effect of intensive insulin therapy on glycemic thresholds for counterregulatory hormone release. Diabetes 37: 901-907

16. Boyle PJ, Schwartz NS, Shah SD, Clutter WE, Cryer PE (1988) Plasma glucose concentrations at the onset of hypoglycemic symptoms in patients with poorly controlled diabetes and nondiabetics. New Engl J Med 318: 1487-1492

17. Amiel SA, Pottinger R, Cunnah DC et al. (1991) Effect of antecedent glucose control on cerebral function during hypoglycemia. Diabetes Care 14: 109-118

Received: 23 October 1992

and in revised form: 12 January 1993

Dr.S.A.Amiel

Unit for Metabolic Medicine

4th Floor, Hunt's House

Guy's Hospital

London

UK 